Journal of Social Sciences 5 (4): 452-459, 2009

ISSN 1549-3652

(C) 2009 Science Publications

\title{
Effects of Critical Knowledge Characteristics on Degree of Inter-Firm Technology Transfer
}

\author{
${ }^{1}$ A.W. Sazali, ${ }^{2}$ A. Haslinda, ${ }^{3}$ U. Jegak, and ${ }^{2}$ C.R. Raduan \\ ${ }^{1}$ Faculty of Management, Multimedia University, 63100 Cyberjaya, Malaysia \\ ${ }^{2}$ Faculty of Economics and Management, University Putra Malaysia, 43400 Selangor, Malaysia \\ ${ }^{3}$ Faculty of Educational Studies, University Putra Malaysia, 43400 Selangor, Malaysia
}

\begin{abstract}
Problem statement: The current issue on inter-firm technology transfer in the developing countries is centered on the efficiency and effectiveness of the transfer process by the Multinationals (MNCs). Thus, organizations in the developing countries are striving hard to collaborate, learn and internalize their foreign partner's technological knowledge by forming strategic alliances or International Joint Ventures (IJVs) as an efficient mean to increase their competitiveness, technological capabilities and potential for local innovation. Knowledge as the critical element underlying technology has become one of the main factors that affects the success and failure of interfirm technology transfer within IJVs which is measured by the degree of technology transferred. Based on the underlying knowledge-based view perspective, this paper aims to empirically examine the effect of three critical knowledge characteristics: Tacitness, complexity and specificity on degree of technology transfer and its two dimensions: Degree of tacit and explicit knowledge. Approach: The theoretical model and hypotheses in this study were tested using empirical data gathered from 128 joint venture companies registered with the Registrar of Companies of Malaysia. Data obtained from the survey questionnaires were analyzed using the correlation coefficients and multiple linear regression analyses. Results: The results revealed that tacitness and complexity as two critical elements of knowledge characteristics have significant effects on both degrees of tacit and explicit knowledge; with complexity recording slightly stronger effect than tacitness. However, although specificity has a strong theoretical foundation, it did not record significant effect. Conclusion: The study has bridged the literature gaps in such that it provides empirical evidence on the effects of three generic knowledge attributes: Tacitness, complexity and specificity on degree of inter-firm technology transfer and its two dimensions: Degree of tacit and explicit knowledge.
\end{abstract}

Key words: Technology transfer, international joint ventures, knowledge-based view, Malaysia

\section{INTRODUCTION}

Past studies have acknowledged the important role of MNCs as the main source of technology. MNCs have been regarded as the most efficient vehicle for transferring technology and knowledge across borders through FDIs and IJVs ${ }^{[12,26]}$. Previous literature has indicated that foreign $\mathrm{MNCs}$ in Malaysia have successfully transferred their technology to local industries ${ }^{[15,32]}$. The technologies transferred by MNCs benefit the host country in terms of achieving long term economic growth ${ }^{[2,26]}$ providing a higher potentials of innovation performance/capabilities ${ }^{[9,20]}$. increasing technological capabilities ${ }^{[14,23]}$, enhancing the competitive advantage ${ }^{[19,38]}$, enhancing the organizational learning effectiveness ${ }^{[8,10]}$, providing a positive effect on productivity ${ }^{[3,22]}$ and increasing the technological development of local industry ${ }^{[27]}$.

Prior to formulating the appropriate technology transfer strategies and policies, there is a need to critically examine one of the technology transfer characteristics: Knowledge characteristics that may have significant influence on the successful and effective implementation of TT particularly technologies transferred through IJVs. In the context of inter-firm TT, success is determined by the substantial amount of technology transferred (level of TT) and the level of technological capacity of the local firms to absorb, assimilate, improve and further develop the newly acquired technology ${ }^{[23]}$. IJVs are viewed as the most efficient mode to transfer technology or knowledge which is organizationally embedded and difficult to transfer through licensing agreements ${ }^{[11,31]}$.

Corresponding Author: Sazali, A.W, Faculty of Management, Multimedia University, 63100 Cyberjaya, Selangor, Malaysia 


\section{J. Social Sci., 5 (4): 452-459, 2009}

Knowledge, as an important element underlies technology, can be learned and transferred between IJVs' partners. IJVs provide both MNCs and local partners an appropriate vehicle to facilitate the transfer of organizational knowledge, particularly for knowledge which is hard to be transferred without the setting up of a JV, such as institutional and cultural knowledge ${ }^{[5]}$. Previous studies on inter-firm knowledge transfer have suggested that: (1) although studies on TT and $\mathrm{KT}$ in strategic alliance have contributed many interesting and valuable theories, they remain empirically under-researched ${ }^{[29]}$, (2) studies on interfirm KT and knowledge acquisition by organizations require more hypothesis development and testing ${ }^{[7]},(3)$ the cross-border TT and KT from MNCs to local firms have not been extensively researched ${ }^{[34]}$ (4) studies on inter-firm knowledge acquisition in alliance have focused heavily on the supplier's, JV or KT perspective $\mathrm{e}^{[3,40,41,57]}$ and (5) fewer studies adopt the local firms or recipient's perspective ${ }^{[46]}$.

Based on the underlying knowledge-based view perspective, this paper aims to empirically examine the effect of three critical knowledge characteristics, specifically, tacitness, complexity and specificity on the degree of technology transfer. The hypotheses of this study are as follows:

- H1: Tacitness as one of the critical elements of knowledge characteristic is negatively related to degree of inter-firm technology transfer in IJVs

- H2: Complexity as one of the critical elements of knowledge characteristic is negatively related to degree of inter-firm technology transfer in IJVs

- H3: Specificity as one of the critical elements of knowledge characteristic is negatively related to degree of inter-firm technology transfer IJVs

Knowledge Characteristics (KCHAR) and degree of inter-firm technology transfer: From the literature review, a number of $\mathrm{KCHAR}$ that have been identified include tacitness, complexity, specificity $^{[8,10,12,16,24,28,30,34,35,40,41]}, \quad$ knowledge relatedness $^{[8]}$, desirability ${ }^{[34]}$ and availability ${ }^{[28]}$. Knowledge tacitness, specificity and complexity have contributed significantly to knowledge ambiguity in imitation $^{[37]}$ and knowledge migration ${ }^{[43]}$. Building on the previous intra-firm knowledge transfer studies $^{[12,28,37,43,47]}$ and inter-firm knowledge transfer studies $^{[9,10,31,34,40,41]}$, this study conceptualizes that the three critical dimensions of KCHAR: Tacitness (TCT), Complexity (COMPLX) and Specificity (SPEC) have a significant negative impact on degree of technology transfer (TTDEG).
The knowledge dimension that appears to be particularly relevant to $\mathrm{TT}$ is 'tacit Vs explicit dimension $^{[4,25]}$, The concept of tacit knowledge (TCT) is derived from the famous work of Polanyi ${ }^{[36]}$ who asserts that "we can know more than what we can tell". Tacit knowledge is knowledge that is non-verbalizable, intuitive and unarticulated, developed through the transfer of context-specific knowledge, embedded in non-standardized and tailored process and is difficult to acquire and exploit ${ }^{[36]}$. Tacit knowledge derives from the accumulated experience and is reflected in the expertise, skills and routines acquired by organizational members over time ${ }^{[28]}$. Past studies have established that tacit knowledge, which includes insights, intuitions and hunches, rule of thumb, gut feeling, personal and organizational skills ${ }^{[33]}$, managerial and marketing expertise $^{[17]}$ is difficult to codify: Where it can only be observed through its application and acquired through practice. Thus, tacit knowledge transfer between individuals is slow, costly and uncertain ${ }^{[13]}$. Acquiring tacit knowledge is subject to time-compression diseconomies: Which means to accelerate tacit knowledge learning is very difficult or perhaps not even possible no matter how much efforts or resources are invested to acquire them within a short period of time $^{[20]}$ because tacit knowledge is unique to the knowledge owner and not codifiable in formulas or manuals and cannot be reverse-engineered easily ${ }^{[47]}$. Tacit knowledge which is hard to formalize, often sticky and not easily visible, is difficult to communicate, transfer and share between the alliance partners as it involves intangible factors embedded in the personal beliefs, experiences and values in an organization $^{[8,9]}$ and internal individual processes like experience, reflection, internalization or individual talents $^{[33]}$, as well as high incremental cost of transferring the knowledge to a specified location in a form usable by a given party ${ }^{[44]}$.

As the second critical element of knowledge characteristic, complexity (COMPLX) has been described from many aspects for example: (1) COMPLX is closely associated with the amount of information required to characterize the item of knowledge in question ${ }^{[28]}$, (2) COMPLX is "a result of the interdependent skills and assets: Which arises from large numbers of technologies, organization routines and individual or team-based experience ${ }^{[37],}$ (3) COMPLX as "the number of interdependent technologies, routines, individuals and resources linked to a particular knowledge or assets ${ }^{[41] "}$ (4) COMPLX as "the number of critical and interacting elements embraced by an entity or activity ${ }^{[12]}$, and (5) COMPLX as "an applied system whose components have multiple 
interactions and constitutes a non-decomposable

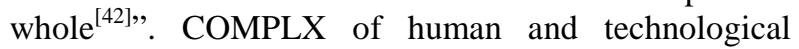
systems produce higher levels of ambiguity which restrains imitation and impedes transferability ${ }^{[37]}$. It is argued that the higher the degree of COMPLX of the manufacturing technology, the more difficult for knowledge to be transferred or imitated ${ }^{[12]}$.

On the other hand, Specificity (SPEC) originally refers to transaction costs asset specificity as popularized by Williamson ${ }^{[45]}$. Asset SPEC which includes site, physical, dedicated and human assets refer to durable investments that are undertaken in support of particular transaction ${ }^{[45]}$. Building on Williamson $^{[45]}$, Reed and DeFillippi ${ }^{[37]}$ define SPEC as "transaction-specific skills and assets that are utilized in production processes and provision of services for particular customers". Through firm-customer relationship, the business actions resulting from the resource and skill deployment (competencies) are highly specific and inter-dependent with the firm's internal or external transaction partners ${ }^{[37]}$. Although sites or physical assets create limited ambiguity to imitation by rivals, dedicated assets such as the plants specifically designed for the production of goods and services for a specific customer and human asset SPEC is linearly and significantly related to ambiguity as these types of asset SPEC create barriers to imitation and are protected by the security and exclusivity of the firm-customer relationship ${ }^{[37]}$. Simonin ${ }^{[41]}$ narrowly views SPEC as "durable investments in specialized equipment, facilities and skilled human resources". Asset SPEC is not only acted as a source of causal ambiguity and barrier to imitation, where technology is difficult to be explicitly articulated ${ }^{[21]}$, but also as a barrier to knowledge transferability ${ }^{[41]}$. The firms' resources and competencies, which are highly specific, are difficult to imitate and transfer as they are embedded in context and idiosyncrasy to the firm ${ }^{[12]}$. Firms create sustainable competitive advantage by developing firms' assets and competencies that are firm-specific, produce complex social relationships i.e., firm-customer relationship, embedded in a firm's history and culture, generate organizational tacit knowledge and time consuming to develop ${ }^{[12,15]}$.

\section{MATERIALS AND METHODS}

Sample Based on the number of IJV companies registered with the Registrar Of Companies (ROC) as at 1st January 2008, the number of IJVs currently operating in Malaysia is 1038 . Out of this, $850 \mathrm{IJVs}$ are considered as active IJVs and 103 IJVs are either dormant or have ceased operation. Since the focus of this study is on inter-firm TT from foreign MNCs to local companies, $85 \mathrm{IJVs}$ were further eliminated from the population frame because the IJVs that have operated more than 2 years and have at least twenty percent $(20 \%)$ of foreign equity are eligible to participate in the survey. Therefore, based on the list provided by ROC, which is considered as the most official and original source of information on foreign investment in Malaysia, it was decided that all IJVs (850) be included in the survey. Data collection was conducted in the period from July 2008 to December 2008 using a self-administered questionnaire. The questionnaires were mailed to 850 active JV companies as listed with ROC using a cover letter. After one month from the posting date the response was not encouraging. By mid July 2008 there were only 70 responses received from the respondents. Thus, in order to increase the response rate the researcher followed-up through numerous phone calls, e-mails, reminders via letters and personal visits to seek the respondents' cooperation in the survey. After intensive efforts were made, by mid November 2008 a total of 145 responses $(17.05 \%)$ were received. Based on literature review, the response rates for mailed questionnaires are usually not encouraging and low (Sakaran, 2003). In the Malaysian context, however, a response rate of $15-25 \%$ is still being considered appropriate and acceptable ${ }^{[39,39]}$. From 145 responses only 128 questionnaires were usable and the balance were returned blank, returned incomplete, or replied but unable to participate in the study.

Instrument and measurement: The main research instrument in this study is the questionnaire. Building on the previous studies on KT and TT, the questionnaire adopts a multi-item scales which have been modified accordingly to suit the context of the study: Inter-firm TT. Except for TTDEG, all the variables are measured using ten-point Likert Scale $(1=$ strongly disagree to $10=$ strongly agree $)$. For TTDEG, this variable is measured using ten-point Likert scale $(1=$ very low transfer to $10=$ substantial transfer). The ten-point Likert Scale was selected because (1) the wider distribution of scores around the mean provides more discriminating power, (2) it is easy to establish covariance between two variables with greater dispersion around their means, (3) it has been well established in academic and industry research and (4) from a model development perspective, a ten-point scale is more preferred ${ }^{[1]}$.

Dependent Variable-Degree of Technology Transfer (TTDEG): Lyles and Salk ${ }^{[10,17,34]}$, Yin and $\mathrm{Boa}^{[46]}$ and Minbaeva ${ }^{[28]}$, this study adopts "a multi-dimensional 


\section{J. Social Sci., 5 (4): 452-459, 2009}

operationalization approach" in measuring this construct. This study operationalizes TTDEG as the transfer of technological knowledge in terms of two dimensions: (1) Tacit knowledge (TCTDEG) in terms of new product/service development, managerial systems and practice, process designs and new marketing expertise and (2) explicit knowledge (EXPDEG) in terms of manufacturing/service techniques/skills, promotion techniques/skills, distribution know-how and purchasing know-how. The respondents were asked to evaluate TTDEG from MNCs to local firms in terms of tacit and explicit dimensions of technological knowledge. The Cronbach Alphas for TCTK and EXPK were 0.96 and 0.97 respectively. The results of Cronbach Alpha were quite similar to that of Hau and Evangelista ${ }^{[6]}$ and Yin and $\mathrm{Bao}^{[46]}$.

\section{Independent variables:}

Tacitness (TCT): This study measures TCT in terms of its two constructs: Codifiability and teachability ${ }^{[12,40,41]}$. For codifiability, multi-item scales are designed to capture the extent to which the technology has been articulated in documents. Two items are adopted from $^{[12]}$ and modified accordingly to suit the context of this study which includes statements as to whether (1) the foreign JV partner's manual describing the technology can be written and (2) large parts of the foreign JV partner's technology are embodied in standard software. Two (2) items are adopted from Simonin ${ }^{[40,41]}$ which include statements whether (1) the foreign JV partner's technology is easily codified and (2) the foreign JV partner's technology is more explicit than tacit. One item is adopted from Pak and Park ${ }^{[34]}$ inquiring whether the partner's technology is hard to verbally transfer. For teachability, the scales are designed to capture the ease by which technology can be learned by the local JV partner. Three (3) items are adapted from Kogut and Zander ${ }^{[12]}$ and modified accordingly to suit the context of the study which include statements whether (1) the local JV firm's personnel can easily learn the technology by communicating with the foreign JV partner's skilled personnel, (2) the local JV local firm's personnel can easily learn the technology by studying a complete set of blueprints and (3) educating and training the JV local firms' personnel is a quick and easy process. The Cronbach Alpha for TCT was slightly higher (0.86) than Simonin's ${ }^{[41]}$ Cronbach Alpha (0.72).

Complexity (COMPLX): Following Simonin ${ }^{[40,41]}$ and Kogut and Zander ${ }^{[12,13]}$, this study adopts a 5 items scale in measuring COMPLX which include statements whether the JV partner's technology is the product of many interdependent techniques, routines, individuals, resources and processes. The Cronbach Alpha for COMPLX was also higher (0.84) as compared to Pak and Park's ${ }^{[34]}$ Cronbach Alpha (0.74).

Specificity (SPEC): To capture SPEC this study adopts a 2 items scale from Simonin ${ }^{[41]}$ in terms of whether (1) the foreign JV partner has invested significantly in specialized equipment and facilities in developing their technology and (2) the foreign JV partner has invested significantly in skilled human resources in developing their technology. Following Pak and Park ${ }^{[34]}$, this study also adopts 1 item scale which includes a statement on whether the technology is difficult to access from the other company. For SPEC the Cronbach Alpha was slightly lower (0.72) as compared to Pak and Park' s ${ }^{\text {[3] }}$ Cronbach Alpha (0.87).

\section{RESULTS}

Table 1 shows the descriptive data of all the variables (mean values, standard deviations, correlations). Table 2 presents the correlation matrix for all measured variables.

From Table 1, there are clearly some associations between independent variables. For all the variables, it was found that there was no multicollinearity problem; where the $\mathrm{T}$ values were ranged between $0.827-0.881$ and the VIF values were between 1.020 and 1.209. Tacitness (TCT) and Complexity (COMPLX) were significantly correlated with degree of tacit knowledge (TCTDEG) $(\mathrm{p}<0.05)$. Although Specificity (SPEC) showed a negative correlation with TCTDEG, however, it was not statistically significant. The correlation results also indicated that both TCT and COMPLX also had significant correlations with EXPDEG ( $p<0.05$ and $\mathrm{p}<0.01$ respectively). Again, although Specificity (SPEC) showed a negative direction as predicted, however, the statistical result was insignificance.

Table 1: Descriptive statistics

\begin{tabular}{lllllll}
\hline Variable & Mean & SD & 1 & 2 & 3 & 4 \\
\hline TCT & 5.36 & 1.58 & 1.000 & & & \\
COMPLX & 6.24 & 1.34 & -0.084 & 1.000 & & \\
SPEC & 3.55 & 1.07 & 0.068 & $0.400^{* *}$ & 1.000 & \\
TCTDEG & 5.91 & 1.45 & $-0.194^{*}$ & $-0.207^{*}$ & -0.012 & 1.000 \\
TCT & 5.93 & 1.35 & 1.000 & & & \\
COMPLX & 5.89 & 1.31 & -0.084 & 1.000 & & \\
SPEC & 4.73 & 1.30 & 0.068 & $0.400^{* *}$ & 1.000 & \\
EXPDEG & 6.47 & 1.34 & $-0.225^{*}$ & $-0.236^{*}$ & -0.118 & 1.000 \\
\hline $\mathrm{n}=128 ; *: \mathrm{p}<0.05 ; * *: \mathrm{p}<0.01$ & & & &
\end{tabular}




\section{J. Social Sci., 5 (4): 452-459, 2009}

Table 2: Results of categorical regression analysis ${ }^{\mathrm{a}}$

\begin{tabular}{lll}
\hline Variable & $\begin{array}{l}\text { Degree of tacit } \\
\text { knowledge }\end{array}$ & $\begin{array}{l}\text { Degree of explicit } \\
\text { knowledge }\end{array}$ \\
\hline (Constant) & $36.359^{* * *}$ & $41.583^{* * *}$ \\
Tacitness & $-0.143^{*}$ & $-0.155^{*}$ \\
Complexity & $-0.355^{*}$ & $-0.333^{*}$ \\
Specificity & 0.165 & 0.002 \\
Squared & 0.098 & 0.116 \\
Adjusted R-squared & 0.064 & 0.082 \\
$\mathrm{~F}$ & $2.840^{*}$ & $3.407^{*}$ \\
\hline a: Cell entries are standardised coefficient & estimates $(\mathrm{n}=128) ;$ \\
$*: \mathrm{p}<0.05 ; * *: \mathrm{p}<0.01 ; * * *: \mathrm{p}<0.001$ &
\end{tabular}

Using the multiple regression analysis, the effects of TCT, COMPLX and SPEC on two dimensions of degree of technology transfer (TCTDEG and EXPDEG) were estimated. As shown in Table 2, tacitness and complexity as two critical components of knowledge characteristics had significant effect on both degrees of tacit and explicit knowledge in inter-firm TT. The regression results indicated that both tacitness and complexity had considerable and significant effects on both dimensions of technology transfer. This is evident by the results of the adjusted $R$-squared and F statistics. As the critical elements of knowledge characteristics, both tacitness and complexity had negative and significant effect on both degrees of tacit and explicit knowledge $(\mathrm{p}<0.05)$. Therefore, $\mathrm{H} 1$ and $\mathrm{H} 2$ are supported thus indicating that the higher level of knowledge tacitness and complexity of the foreign partners' technology contributes to the lesser degree of tacit and explicit knowledge that are being transferred to the recipients/local partners in IJVs.

Interestingly, although specificity has been strongly highlighted by previous literature of its significance, it has failed to provide any significant effects on both degree of tacit and explicit knowledge ( $>$ >0.05). In this study, specificity as one of the critical elements of knowledge characteristic has not really effected degrees of tacit and explicit knowledge in inter-firm TT in IJVs though the direction was correctly predicted. Thus, H3 is not supported.

\section{DISCUSSION}

Based on the underlying knowledge-based view perspective, this study attempts to provide empirical evidence as to the effects of three critical knowledge characteristics (tacitness, complexity and specificity) on degree of tacit and explicit knowledge in the inter-firm TT through IJVs. This paper has specifically addressed the effects of knowledge characteristics on generic knowledge attributes (tacitness and explicitness) as highlighted by Pak and Park ${ }^{[34]}$. Other than examining the relationships between key knowledge characteristics and degree of technology transfer (both degrees of tacit and explicit knowledge), this study also had extended the previous findings on knowledge specific attributes ${ }^{[12,41]}$ which suggest that tacitness or ambiguity of knowledge is rather difficult to transfer between strategic alliance partners of joint ventures. The consistent results of the significant effects of tacitness and complexity on both degrees of tacit and explicit knowledge were different from that of Pak and Park ${ }^{[34]}$; where they found that the effects of specificity and desirability on manufacturing-processing (explicit knowledge) were more dominant than new product development (tacit knowledge). The results in the present study were quite interesting given that although explicit knowledge is mostly codified in the form of blueprints, instructions, formulas or standard manuals by the supplier; which allows for more easy transfer of technology, however, explicit knowledge still implicitly consists of an intrinsic tacit element/value in which to accelerate the transfer of explicit knowledge would involve various organizational and group levels of involvement ${ }^{[8]}$. The results suggest that explicit knowledge transfer of a highly tacit and complex technology/knowledge requires not only learning by doing by the recipient but also active involvement of the teacher/supplier ${ }^{[18]}$. Overall, the findings confirm and support the previous empirical results of the effect of KCHAR on knowledge transfer where knowledgespecific attributes such as tacitness or ambiguous knowledge are more difficult to transfer for international ventures ${ }^{[12,28,34,37,41,43]}$.

The results of present study also suggest that tacitness and complexity had negatively affected the degree (level) of technologies (TCTDEG and EXPDEG) that were intended to be transferred to the recipient because the technology supplier's technologies were well embodied within the component of their competencies, non-codifiable, highly personal and deeply rooted in action, commitment and involvement within a specific context ${ }^{[33,37]}$. Tacitness and complexity of technology involved the intangible factors embedded in the personal beliefs, experiences and values in an organization which caused the technology/knowledge to be difficult to be formalized, communicated, transferred and shared between the alliance or JV partners ${ }^{[8,9]}$. On the insignificance of specificity, the results seemed to concur with Simonin's ${ }^{[4]]}$ suggestion that the construct's (SPEC) lack of effect needs to be further investigated for other types of competencies thus should not only be restricted to technological knowledge. 


\section{J. Social Sci., 5 (4): 452-459, 2009}

\section{CONCLUSION}

With respect to the study's limitation, due to constraint of resources this study has mainly relied on responses obtained from the top management level of the JVs. Organizational members representing different levels and functions may also have unique contributions to make in assessing tacitness, complexity, specificity and degree of technology transfer (both TCTDEG and EXPDEG). Thus, the scope of respondents could have been broadened to include the middle and lower management levels in the JVs such as the technical, administrative and production managers (1) who are directly involved in daily implementation of TT between foreign and local partners and (2) who may have different perspectives about technology transfer. Second, as the major limitation of many organization studies in Malaysia, the response rate in terms of the number of usable questionnaires, though sufficient, was not encouraging. The low level of awareness among the respondents was the main obstacle to the study. A higher response rate could have made the findings more statistically accurate. Thus, the results in this study require careful and cautious interpretation before they can be generalized. Third, consistent with the literature which suggests that JVs in the developing countries are more unstable than JVs in the developed countries, the nature of relationship between JV partners could have affected the results tremendously. The responses have a tendency to be biased should the respondents perceived that the JVs were competitive in nature rather than collaborative. The subjectivity of the nature of relationship thus is difficult to capture. In-depth information on this issue cannot be obtained by the survey method. This limitation could only be overcome through multiple level interviews and observations. Finally, the types of technologies under investigation were confined to tacit and explicit knowledge. This study can be replicated to cover other dimensions of value chain activities such as marketing, production or management technology. Such researches would help to generalize the findings of this study.

Despite the study's limitations, the results and findings of this study constitute a detailed empirical attempt to respond to the need for statistical evidence that has typically been lacking in inter-firm TT literature. While this study focused on degree of interfirm TT, by using the holistic approach and longitudal data, a replicating study could be conducted to further examine the effects of knowledge, technology recipient, technology recipient and relationship characteristics on level of innovation, competitiveness, productivity and technological capabilities of local firms which may also include the effect by other individual dimensions of TT characteristics that have strong theoretical foundation but either have not been tested or failed to receive statistical support. The above relationship could also be extended to other formal inter-firm TT's agents such as FDIs and licensing. Second, the results and findings of this study show significant effects of knowledge characteristics (tacitness and complexity) on two dimensions of TTDEG namely tacit and explicit knowledge. The tacit and explicit dimensions of technology could also cover other dimensions of supply chain activities. Thus, it is worthwhile to find out the relationships and effects of all TT characteristics (knowledge, technology recipient, technology supplier and relationship) on other dimensions of tacit and explicit technology/knowledge of supply chain such as production, marketing, management and distribution. Third, while JVs in developing countries are perceived as unstable organization, further study could investigate the relationships and effects of degree of TT on learning outcomes, asymmetric bargaining power, stability of JV and equity ownership of the local firms.

Finally, this study has contributed new insights to inter-firm TT literature by establishing effects of knowledge characteristics-degree of technology transfer relationship. Thus, it is also worthwhile to investigate further the effects of several established moderating variables such as organizational culture, collaborative know-how, prior JV experience and learning capacity on the relationship thus providing further information on the boundary conditions of the relationship.

\section{REFERENCES}

1. Allen, D.R. and T.R. Rao, 2000. Analysis of Customer Satisfaction Data. America Society for Quality, United States of America, ISBN: 13: 9780873894531.

2. Blomstrom, M., 2001. Multinational Firms, Competitions and Productivity in Host-Country Markets. Int. J. Technol. Manage., 22 : 435-454. DOI: 10.1504/IJTM.2001.002972

3. Caves, R.E., 1974. Multinational firms, competition and productivity in host-country markets. Economica, 41: 176-193.

4. Grant, R.M., 1996. Toward a Knowledge-based theory of the firm. Strat. Manage. J., 17: 109-22.

5. Harrigan, K.R., 1984. Joint ventures and global strategies. Columbia J. World Bus., 19: 7-16.

6. Hau, L.N. and F. Evangelista, 2007. Acquiring tacit and explicit marketing knowledge from foreign partners in IJVs. J. Bus. Res., 60: 1152-1165. DOI:10.1016/j.jbusres.2007.04.006 


\section{J. Social Sci., 5 (4): 452-459, 2009}

7. Huber, G.P., 1991. Organizational learning: The contributing processes and the literature. Org. Sci., 2: 88-115. DOI: 10.1287/orsc.2.1.88

8. Inkpen, A.C., 2000. Learning through joint ventures: A8. framework of knowledge acquisition. J. Manage. Stud., 37(7): 1019-1043. DOI: 10.1111/1467-6486.00215

9. Inkpen, A.C., 1998. Learning and knowledge acquisition through international strategic alliances. Acad. Manage. Execut., 12: 69-80. DOI: 10.1111/1467-6486.00215

10. Inkpen, A.C. and A. Dinur, 1998. Knowledge ma11.nagement processes and international joint ventures. Org. Sci., 9: 454-468. DOI: 10.1287/orsc.9.4.454

11. Kogut, B., 1988. Joint ventures: Theoretical and empirical perspectives. Strat. Manage. J., 9: 319-32. DOI: $10.1002 / \mathrm{smj} .4250090403$

12. Kogut, B. and U. Zander, 1993. Knowledge of the firm and the evolutionary theory of the multinational corporation. J. Int. Bus. Stud., 24: 625-646. DOI:10.1057/palgrave.jibs.8490248

13. Kogut, B. and U. Zander, 1992. Knowledge of the firm, combinative capabilities and the replication of technology. Org. Sci., 3: 383-97. DOI:10.1057/palgrave.jibs.8490248

14. Kumar, V., U. Kumar and A. Persaud, 1999. Building technological capability through importing technology: The case of indonesian manufacturing industry. J. Technol. Transfer., 24: 81-96. DOI: 10.1023/A: 1007728921126

15. Lado, A. and M. Wilson, 1994. Human resource systems and sustained competitive advantage: A competency-based perspective. Acad. Manage. Rev., 19: 699-727.

16. Lai, Y.W. and S. Narayanan, 1997. The quest for technological competence via MNCs: A Malaysian case study. Asian Econ. J., 11: 407-422. DOI: 10.1111/1467-8381.00045

17. Lane, P. J., J.E. Salk and M.A. Lyles, 2001. Absorptive capacity, learning and performance in international joint ventures. Strat. Manage. J., 22: 1139-61. DOI: $10.1002 / \mathrm{smj} .206$

18. Lane, P.J. and M. Lubatkin, 1998. Relative absorptive capacity and interorganizational learning. Strat. Manage. J., 19: 461-77. DOI: 10.1002/(SICI)10970266(199805)19:5<461::AIDSMJ953>3.0.CO;2-L

19. Liao, S.H. and T.C. Hu, 2007. Knowledge transfer and competitive advantage on environmental uncertainty: An Empirical study of the Taiwan's industry. Technovation, 27: 402-411. DOI: 10.1016/j.technovation.2007.02.005
20. Lin, W.B., 2003. Technology transfer as technological learning: A source of competitive advantage for firms with limited $R$ and $D$ resources. R D Manage., 33: 327-341. DOI: 10.1111/1467-9310.00301

21. Lippman, S.A. and R.P. Rumelt, 1982. Uncertain imitability: An analysis of interfirm differences in efficiency under competition. Bell. J. Econ., 13: 418-438.

22. Liu, X. and C. Wang, 2003. Does foreign direct investment facilitate technological progress? Evidence from Chinese industries. Res. Policy, 32: 954-953. DOI:10.1057/palgrave.jibs.8490155

23. Madanmohan, T.R., U. Kumar and V. Kumar, 2004. Import-led technological capability: A comparative analysis of Indian and indonesian manufacturing firms. Technovation, 24: 979-993. DOI: 10.1016/S0166-4972(03)00030-0

24. Makhija, M.V. and U. Ganesh, 1997. The relationship between control and partner learningrelated joint ventures. Org. Sci., 8: 508-527. DOI: 10.1287/orsc.8.5.508

25. Marcotte, C. and J. Niossi, 2000. Technology transfer to China: The issues of knowledge and learning. J. Technol. Transfer, 25: 43-57. DOI: 10.1023/A:1007887004249

26. Marton, K., 1986. Multinationals, Technology, and Industrialization. Lexington, Hearth. MA., ISBN13: 978-0892328390.

27. Markusen, J.R. and A.J. Venables, 1999. Foreign direct investment as a catalyst for industrial development. Eur. Econ. Rev., 43: 335-356.

28. Minbaeva, D., 2007. Knowledge transfer in multinationals. Manage. Int. Rev., 47: 567-593. DOI: $10.1007 / \mathrm{s} 11575-007-0030-4$

29. Mjoen H. and S. Tallman, 1997. Control and performance in international joint ventures. Org. Sci., 8: 257-274. DOI: 10.1287/orsc.8.3.257

30. Mohr, J.J. and S. Sengupta, 2002. Managing the paradox of inter firm learning: The role of governance mechanisms. J. Bus. Ind. Market., 17: 282-301. DOI: 10.1108/08858620210431688

31. Mowery, D.C., J.E. Oxley and B.S. Silverman, 1996. Strategic alliances and interfirm knowledge transfer. Strat. Manage. J., 17: 77-91.

32. Narayanan, S. and Y.W. Lai, 2000. Technological maturity and development without research: The challenge for Malaysian manufacturing. Dev. Change, 31: 435-457. DOI: 10.1111/14677660.00161

33. Nonaka, I., 1994. A dynamic theory of organizational knowledge creation. Org. Sci., 5: 14-37. DOI: 10.1287/orsc.5.1.14 
34. Pak, Y. and Y. Park, 2004. A framework of knowledge transfer in cross-border joint ventures: An empirical test of the Korean context. Manage. Int. Rev., 44: 435-455.

35. Parise, S. and J.C. Henderson, 2001. Knowledge resource exchange in strategic alliances. IBM Syst. J., 40: 908-924.

36. Polanyi, M., 1967. The Tacit Dimension. Anchor, Garden City, New York. ISBN: 13: 9780226672984.

37. Reed, R. and R.J. DeFillippi, 1990. Causal ambiguity, barriers to imitation and sustainable competitive advantage. Acad. Manage. Rev., 15: 88-102.

38. Rodriguez, J.L. and R.M.G. Rodriguez, 2005. Technology and export behavior: A resource-based view approach. Int. Bus. Rev., 14: 539-557. DOI:10.1016/j.ibusrev.2005.07.002

39. Rozhan, O., Rahayu and Rashidah, 2001. Great expectation: CEO's perception of the performance gap of the HRM functions in the Malaysian manufacturing sector. Person. Rev., 30: 61-80. DOI: $10.1108 / 00483480110380145$

40. Simonin, B.L., 2004. An empirical investigation of the process of knowledge transfer in international strategic alliances. J. Int. Bus. Stud., 35: 407-27. DOI: 10. 1057/palgrave.jibs.840091

41. Simonin, B.L., 1999a. Ambiguity and the process of knowledge transfer in strategic alliances. Strat. Manage. J., 20: 595-623. DOI: 10.1002/(SICI) 0970266(199907)20:7<595:AIDSMJ >3.0.CO;2-5

42. Singh, K., 1997. The impact of technological complexity and interfirm on business survival. Acad. Manage. J., 40: 339-367.

43. Szulanski, G., 1996. Exploring internal stickiness: Impediments to the transfer of best practice within the firm. Strat. Manage. J., 17: 27-43.
44. Von Hippel, E., 1994. Sticky information and the locus of problem solving: Implication for innovation. Manage. Sci., 40: 429-439. DOI: $10.1287 / \mathrm{mnsc} .40 .4 .429$

45. Williamson, O.E., 1985. The Economic Institutions of Capitalism: Firms, Markets, Relational Contracting. Free Press, New York, ISBN-13: 9780029348208.

46. Yin, E. and Y. Bao, 2006. The acquisition of tacit knowledge in China: An empirical analysis of the 'supplier-side individual level' and 'recipient-side' factors. Manage. Int. Rev., 46: 327-348. DOI: 10.1007/s11575-006-0050-5

47. Zander, U. and B. Kogut, 1995. Knowledge and the speed of the transfer and imitation of organizational capabilities: An empirical test. Org. Sci., 6: 76-92. DOI: 10.1287/orsc.6.1.76 